\title{
PARAMETER NERACA HAYATI DAN PERTUMBUHAN POPULASI KUTU PUTIH PHENACOCCUS MANIHOTI MATILE-FERRERO (HEMIPTERA: PSEUDOCOCCIDAE) PADA DUA VARIETAS UBI KAYU
}

\author{
Nila Wardani ${ }^{1}$, Aunu Rauf ${ }^{2}$, I Wayan Winasa ${ }^{2}$, \& Sugeng Santoso ${ }^{2}$ \\ ${ }^{1}$ Balai Pengkajian Teknologi Pertanian Lampung, \\ Jl. ZA. Pagar Alam No. IA, Bandar Lampung \\ ${ }^{2}$ Departemen Proteksi Tanaman, Fakultas Pertanian, Institut Pertanian Bogor, \\ Kampus IPB-Darmaga, Bogor 16680 \\ E-mail: aunu@indo.net.id
}

\begin{abstract}
The life history and population growth parameters of mealybug Phenacoccus manihoti Matile-Ferrero (Hemiptera: Pseudococcidae) on two cassava varieties. The development, reproduction, and population growth parameters of the cassava mealybug, Phenacoccus manihoti Matile-Ferrero (Hemiptera: Pseudococcidae) on two cassava varieties were studied in laboratory. The varieties tested were UJ-5 with high cyanide content (>100 mg per kg) dan Adira-1 with low cyanide content ( $27.5 \mathrm{mg}$ per kg). Our research revealed that $P$. manihoti performances were highly affected by cassava varieties. Incubation period of eggs of $P$. manihoti were $7.93 \pm 0.09$ and $8.33 \pm 0.11$ days, nymphal development periode $12.32 \pm 0.13$ and $15.67 \pm 0.13$ days, respectively on UJ-5 and Adira- 1 . Fecundity averaged $386.37 \pm 5.83$ on UJ-5 and $318.67 \pm 2.81$ eggs on Adira- 1 . Intrinsic rate of increase $\left(\mathrm{r}_{\mathrm{m}}\right)$ were $0.258 \pm 0.001$ on UJ-5 and $0.220 \pm 0.001$ on Adira- 1 . Mean generation time (T) on UJ-5 and Adira-1 were $22.795 \pm 0.050$ and $25.532 \pm 0.047$ days, repectively. Our findings showed that variety UJ-5 was more suitable for development and population growth of the cassava mealybug.
\end{abstract}

Key words: cassava, mealybug, Phenacoccus manihoti

\begin{abstract}
ABSTRAK
Parameter neraca hayati dan pertumbuhan populasi kutu putih Phenacoccus manihoti matile-ferrero (Hemiptera: Pseudococcidae) pada dua varietas ubi kayu. Parameter perkembangan, reproduksi, dan pertumbuhan populasi kutu putih ubi kayu, Phenacoccus manihoti Matile-Ferrero (Hemiptera: Pseudococcidae) pada dua varietas ubi kayu diteliti di laboratorium. Varietas ubi kayu yang diuji yaitu UJ-5 dengan kandungan sianida tinggi (>100mg) dan Adira-1 dengan kandungan sianida rendah $(27,5 \mathrm{mg})$. Hasil penelitian mengungkapkan bahwa kehidupan P. manihoti sangat dipengaruhi oleh varietas ubi kayu. Masa inkubasi telur $P$. manihoti berlangsung 7,93 $\pm 0,09$ dan 8,33 $\pm 0,11$ hari, masa perkembangan nimfa 12,32 $\pm 0,13$ dan 15,67 $\pm 0,13$ hari, berturut-turut pada varietas UJ-5 dan Adira-1. Rataan keperidian adalah 386,37 $\pm 5,83$ pada UJ-5 dan 318,67 $\pm 2,81$ butir telur pada Adira-1. Laju pertambahan intrinsik $\left(\mathrm{r}_{\mathrm{m}}\right)$ adalah $0,258 \pm 0,001$ pada UJ-5 dan $0,220 \pm 0,001$ pada Adira- 1 . Rataan masa generasi (T) pada UJ-5 dan Adira- 1 berturut-turut 22,795 $\pm 0,050$ dan 25,532 $\pm 0,047$ hari. Keseluruhan hasil penelitian menunjukkan bahwa varietas UJ-5 lebih sesuai bagi perkembangan dan pertumbuhan populasi kutu putih ubi kayu.
\end{abstract}

Kata kunci: ubi kayu, kutu putih, Phenacoccus manihoti

\section{PENDAHULUAN}

Kutu putih ubi kayu, Phenacoccus manihoti Matile-Ferrero (Hemiptera: Pseudococcidae), merupakan hama yang paling merugikan pada pertanaman ubi kayu di banyak negara di dunia (Belloti et al., 1999). Persebaran hama ini awalnya terbatas hanya di Amerika Selatan, tetapi kemudian menyebar ke Afrika pada awal tahun 1970-an yang menimbulkan kerusakan berat dan kerugian ekonomis (Nwanze et al.,
1979). Kutu P. manihoti masuk ke Asia pada tahun 2008, yaitu ketika pertama kali ditemukan di Thailand. Hama kemudian menyebar ke beberapa negara di sekitarnya seperti Kamboja, Laos, dan Vietnam (Winotai et al., 2010, Parsa et al., 2012). Di Indonesia kutu P. manihoti pertama kali ditemukan di Bogor pada pertengahan tahun 2010 (Rauf, 2011).

Reproduksi P. manihoti bersifat partenogenetik telitoki yaitu menghasilkan keturunan yang semuanya betina (Catalayud \& Le Ru, 2006). Setiap induk 
menghasilkan telur sebanyak sekitar 500 butir yang terdapat dalam ovisak atau kantung telur. Ovisak tampak berupa gumpalan kapas berwarna putih pada ujung abdomen. Telur menetas menjadi nimfa instar-1, disebut crawler, yang aktif bergerak. Nimfa berganti kulit sebanyak tiga kali sebelum menjadi imago. Instar-2 dan selanjutnya serta imago hidup menetap dengan cara mengisap cairan tanaman. Pada kondisi laboratorium, masa perkembangan dari sejak telur diletakkan hingga muncul imago berlangsung sekitar 21 hari (Nwanze, 1978).

Serangan kutu P. manihoti umumnya terjadi pada bagian pucuk. Pada kerapatan populasi yang sangat tinggi seperti yang biasa terjadi pada musim kemarau, serangan meyebabkan pucuk mengeriting, ruas buku memendek, dan tanaman menjadi kerdil. Serangan berat dapat menyebabkan kehilangan hasil hingga $80 \%$ seperti yang terjadi di Afrika (Nwanze, 1982). Hingga kini belum dijumpai adanya varietas yang resisten penuh terhadap P. manihoti (Soysouvanh \& Siri, 2013). Sementara itu dilaporkan bahwa ketahanan varietas ubi kayu terhadap kutu putih berkaitan dengan keberadaan senyawa sekunder seperti sianida (Catalayud et al., 1994a).

Berdasarkan kandungan sianida, ubi kayu dikelompokkan ke dalam golongan pahit dan tidak pahit. Ubi kayu golongan tidak pahit digunakan untuk konsumsi langsung atau bahan tapioka, sedangkan golongan pahit untuk keperluan industri tapioka dan bioetanol (Balitkabi, 2005). Pada saat ini varietas UJ-5 yang kadar sianidanya tinggi banyak diusahakan di Lampung dan Jawa Timur untuk memenuhi kebutuhan pabrik bioetanol. Tidak diketahui dengan pasti bagaimana kehidupan kutu $P$. manihoti pada varietas ubi kayu yang berbeda kadar sianidanya. Secara umum, perkembangan serangga, sintasan, keperidian, dan berbagai parameter pertumbuhan populasi dipengaruhi oleh kualitas tumbuhan inang (Awmack \& Leather, 2002).

Penelitian bertujuan mempelajari pengaruh varietas ubi kayu dengan kadar sianida berbeda terhadap masa perkembangan telur, nimfa, imago, dan keperidian, serta terhadap berbagai parameter pertumbuhan populasi $P$. manihoti. Hasil yang diperoleh dari penelitian ini diharapkan dapat menyediakan informasi dasar untuk perancangan program pengelolaan hama terpadu kutu $P$. manihoti pada pertanaman ubi kayu.

\section{METODE PENELITIAN}

Tempat dan Waktu. Penelitian dilakukan di Laboratorium Ekologi, Departemen Proteksi Tanaman,
Fakultas Pertanian, Institut Pertanian Bogor dari bulan Juli sampai Oktober 2012. Selama penelitian berlangsung rata-rata suhu harian $29,5^{\circ} \mathrm{C}$ (kisaran $28,3-30,7^{\circ} \mathrm{C}$ ) dan kelembaban relatif 59,3\% (kisaran 51-66\%).

Penyiapan Tumbuhan Inang. Pada penelitian ini digunakan ubi kayu varietas UJ-5 dan Adira-1 yang memiliki kandungan senyawa sianida yang berbeda. Varietas UJ-5 memiliki kadar sianida yang tinggi (> 100 mg per kg), sedangkan Adira-1 mengandung sianida yang rendah (27,5 mg per kg) (Balitkabi, 2005). Kedua varietas ini diperoleh dari Balai Penelitian Kacangkacangan dan Umbi-umbian, Malang. Stek ubi kayu sepanjang kurang lebih $20 \mathrm{~cm}$ dimasukkan ke dalam gelas plastik (diameter $8 \mathrm{~cm}$, tinggi $10 \mathrm{~cm}$ ), melalui penutupnya yang telah dilubangi terlebih dahulu. Sebelumnya gelas diisi air keran sekitar 2/3 dari volume gelas. Stek dibiarkan tumbuh hingga muncul daun. Stek siap digunakan untuk percobaan setelah berdaun sempurna atau berumur kurang lebih satu bulan. Pada penelitian ini digunakan 100 stek ubi kayu untuk setiap varietas sebagai ulangan.

Masa Perkembangan Telur, Nimfa, Imago dan Keperidian. Untuk menentukan lama stadia telur dilakukan prosedur sebagai berikut. Masing-masing empat ekor imago kutu putih dipelihara pada stek ubi kayu varietas UJ-5 dan Adira-1, dan dibiarkan meletakkan telur. Telur yang diletakkan pada hari yang sama, dengan bantuan kuas halus, kemudian dimasukkan ke dalam cawan Petri dan ditunggu sampai telur menetas. Lama waktu yang diperlukan dari sejak telur diletakkan hingga menetas dicatat, yang didasarkan pada 100 ekor nimfa instar-1 yang muncul.

Pengamatan masa perkembangan nimfa, imago dan keperidian ditentukan melalui percobaan berikut ini. Seekor nimfa instar-1 kutu putih yang baru keluar dari telur diinfestasikan dengan bantuan kuas halus pada setiap stek ubi kayu. Masing-masing stek kemudian disungkup dengan kurungan plastik (tinggi $50 \mathrm{~cm}$, diameter $15 \mathrm{~cm}$ ) dengan penutup kain kasa pada bagian atasnya. Perkembangan nimfa diamati setiap hari. hingga menjadi imago. Pergantian instar ditandai oleh adanya eksuvia yang berwarna putih yang menempel pada permukaan daun.

Imago yang terbentuk diamati setiap hari hingga mati, yang dicirikan oleh tubuhnya yang mengkerut dan bila disentuh tidak bergerak. Saat imago muncul sampai terbentuk kantung telur dicatat sebagai masa praoviposisi. Karena sulitnya menghitung butiran telur, keperidian didasarkan pada banyaknya nimfa instar-1 
yang terbentuk setiap hari. Persentase penetasan telur dilakukan dengan cara menghitung semua nimfa yang keluar dari kantung telur, kemudian sisa telur yang tidak menetas yang terdapat pada kantung telur dicatat. Nimfa instar-1 yang keluar bersamaan dari kantung telur diasumsikan diletakkan pada saat yang bersamaan. Oleh karena itu, masa oviposisi dihitung berdasarkan lamanya masa kemunculan nimfa instar-1.

Analisis Data. Uji t digunakan untuk memeriksa pengaruh varietas ubi kayu terhadap masa perkembangan telur dan nimfa, masa hidup imago, dan keperidian, dengan bantuan SPSS 11.5. Data kesintasan $\left(1_{\mathrm{x}}\right)$ dan banyaknya telur yang diletakkan $\left(\mathrm{m}_{\mathrm{x}}\right)$ per hari digunakan untuk menyusun neraca hayati. Kemudian dihitung berbagai parameter neraca hayati seperti laju reproduksi bersih $\left(\mathrm{Ro}=\sum 1_{\mathrm{x}} \mathrm{m}_{\mathrm{x}}\right)$, rataan masa generasi $\left(\mathrm{T}=\ln \mathrm{Ro} / \mathrm{r}_{\mathrm{m}}\right)$, laju pertambahan intrinsik $\left(\mathrm{r}_{\mathrm{m}}=\mathrm{e}^{-\mathrm{rx}} 1_{\mathrm{x}} \mathrm{m}_{\mathrm{x}}\right.$ $=1)$, laju pertambahan terbatas $\left(\lambda=e^{r}\right)$, dan masa ganda $\left(\mathrm{Dt}=\ln 2 / \mathrm{r}_{\mathrm{m}}\right.$ ), berdasarkan metode Birch (1948). Seluruh parameter ini dan ragamnya diduga dengan menggunakan program LIFETABLE.SAS yang dikembangkan oleh Maia et al. (2000).

\section{HASIL DAN PEMBAHASAN}

Masa Perkembangan Pradewasa. Masa perkembangan pradewasa dari sejak telur diletakkan hingga terbentuk imago dipengaruhi secara nyata oleh varietas ubi kayu. Pada UJ-5 masa perkembangan telur, nimfa instar-1, instar-2, dan instar-3 lebih singkat dibandingkan pada Adira-1 (Tabel 1). Perkembangan keseluruhan instar nimfa berlangsung 12,32 hari pada UJ-5 dan 15,67 hari pada Adira-1, atau sekitar 3 hari lebih cepat pada varietas ubi kayu dengan kadar sianida tinggi. Bila masa perkembangan telur dan nimfa digabung, maka masa perkembangan pradewasa sekitar 20 dan 24 hari, berturut-turut pada UJ-5 dan Adira-1.

Masa Hidup Imago, Keperidian dan Penetasan Telur. Varietas ubi kayu yang diuji berpengaruh nyata terhadap masa praoviposisi, masa oviposisi, keperidian, dan persentase penetasan telur $P$. manihoti. Masa praoviposisi $P$. manihoti pada UJ-5 (2,49 hari) sekitar satu hari lebih singkat dibandingkan pada Adira-1 (3,20 hari) (Tabel 2). Sebaliknya masa oviposisi sekitar 3/4 hari lebih lama pada UJ-5 (9,82 hari) dibandingkan pada

Tabel 1. Rataan masa perkembangan pradewasa $(\mathrm{x} \pm \mathrm{SE})$ kutu Phenacoccus manihoti pada dua varietas ubi kayu

\begin{tabular}{cccccc}
\hline Varietas & \multicolumn{5}{c}{ Masa perkembangan stadia (hari) } \\
\cline { 2 - 6 } & Telur & Nimfa-1 & Nimfa-2 & Nimfa-3 & Nimfa \\
\hline UJ-5 & $7,93 \pm 0,09$ & $4,05 \pm 0,09$ & $4,40 \pm 0,08$ & $3,87 \pm 0,11$ & $12,32 \pm 0,13$ \\
Adira-1 & $8,33 \pm 0,11$ & $6,23 \pm 0,08$ & $4,92 \pm 0,10$ & $4,52 \pm 0,10$ & $15,67 \pm 0,13$ \\
$\mathrm{t}$ & $-2,79$ & $-17,57$ & $-3,93$ & $-4,23$ & 17,97 \\
$\mathrm{db}$ & 189,9 & 198 & 198 & 198 & 198 \\
$\mathrm{P}$ & $<0,006$ & $<0,000$ & $<0,000$ & $<0,000$ & $<0,000$ \\
\hline
\end{tabular}

Tabel 2. Rataan masa hidup imago, keperidian, penetasan telur ( $\pm \mathrm{SE}$ ) kutu Phenacoccus manihoti pada dua varietas ubi kayu

\begin{tabular}{cccccc}
\hline & \multicolumn{5}{c}{ Imago betina } \\
\cline { 2 - 6 } Varietas & $\begin{array}{c}\text { Masa } \\
\text { praoviposisi } \\
\text { (hari) }\end{array}$ & $\begin{array}{c}\text { Masa oviposisi } \\
\text { (hari) }\end{array}$ & $\begin{array}{c}\text { Masa hidup } \\
\text { (hari) }\end{array}$ & $\begin{array}{c}\text { Kepiridian } \\
\text { (butir) }\end{array}$ & $\begin{array}{c}\text { Penetasan telur } \\
(\%)\end{array}$ \\
\hline UJ-5 & $2,49 \pm 0,09$ & $9,82 \pm 0,28$ & $20,24 \pm 0,24$ & $386,37 \pm 5,83$ & $98,33 \pm 0,09$ \\
Adira-1 & $3,20 \pm 0,11$ & $9,06 \pm 0,21$ & $20,53 \pm 0,18$ & $318,67 \pm 2,81$ & $96,81 \pm 0,14$ \\
t & $-4,85$ & 2,23 & $-0,95$ & 10,46 & 9,09 \\
db & 182 & 171,2 & 171,1 & 135,1 & 182 \\
$\mathrm{P}$ & $<0,000$ & 0,027 & 0,342 & $<0,000$ & $<0,000$ \\
\hline
\end{tabular}


Adira-1 (9,06 hari). Kedua varietas ubi kayu yang diuji tidak berpengaruh nyata $(\mathrm{P}=0,342)$ terhadap masa hidup imago, yaitu rata-rata 20 hari. Walaupun demikian, keperidian $P$. manihoti lebih tinggi (386 butir) pada UJ5 dibandingkan pada Adira-1 (318 butir). Begitu pula rataan penetasan telur $P$. manihoti lebih tinggi pada UJ5 (98\%) daripada Adira-1 (96\%).

Keperidian Harian dan Sintasan. Kurva keperidian harian $\left(\mathrm{m}_{\mathrm{x}}\right)$ mencapai puncaknya beberapa hari setelah reproduksi dimulai dan berbeda di antara dua varietas ubi kayu (Gambar 1 ). Pada varietas UJ-5, kutu putih P. manihoti mulai meletakkan telur pada hari ke-18, dengan puncaknya (49 butir) terjadi pada hari ke-22.
Pada varietas Adira-1, P. manihoti meletakkan telur mulai hari ke -21 dengan puncaknya (43 butir) pada hari ke-27.

Kurva sintasan harian $\left(1_{x}\right)$ memperlihatkan pola tipe I, yaitu kematian sebagian besar terjadi pada umur tua (Gambar 1). Pada varietas UJ-5 sebanyak 5\% nimfa tidak berhasil menjadi imago, sedangkan pada varietas Adira-1 lebih tinggi yaitu $11 \%$. Pada kedua varietas, kematian kutu putih sebanyak $50 \%$ terjadi pada hari ke45, dan seluruh kutu mati pada hari ke-46.

Parameter Pertumbuhan Populasi. Perbedaan varietas ubi kayu berpengaruh sangat nyata $(\mathrm{P}<0.0001)$ terhadap laju reproduksi bersih (Ro), laju pertambahan
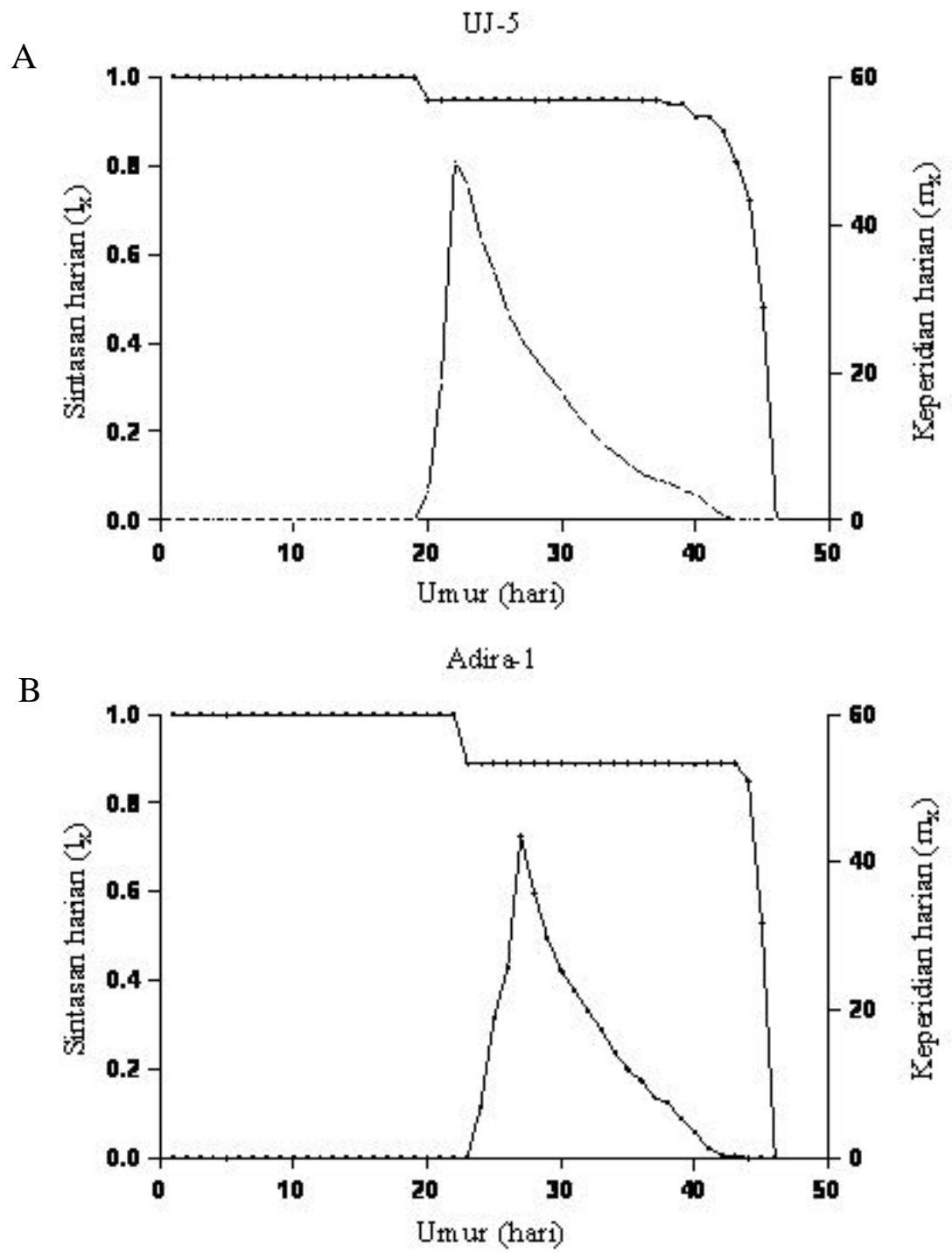

Gambar 1. Keperidian harian $\left(\mathrm{m}_{\mathrm{x}}\right)$ dan sintasan $\left(1_{\mathrm{x}}\right)$ kutu putih Phenacoccus manihoti pada ubi kayu varietas UJ-5 (A) dan Adira-1 (B) 
intrinsik $\left(r_{m}\right)$, rataan masa generasi $(T)$, masa ganda (Dt), dan laju pertambahan terbatas $(\lambda)$. Laju reprodukai bersih (Ro) $P$. manihoti pada varietas UJ-5 adalah 1.3 kali lipat lebih tinggi dibandingkan pada varietas Adira1 (Tabel 3). Begitu pula parameter pertumbuhan populasi lainnya (rm, Dt, $\lambda$ ) lebih tinggi pada UJ-5. Sebaliknya, masa generasi (T) P. manihoti sekitar tiga hari lebih singkat pada varietas UJ-5 dibandingkan pada Adira-1.

Pengetahuan tentang siklus hidup hama dalam kaitan dengan tumbuhan inang diperlukan untuk memahami perkembangan dan kemelimpahan kutu putih P. manihoti pada pertanaman ubi kayu di lapangan. Untuk hama yang bersifat monofag seperti P. manihoti, kehidupannya dapat dipengaruhi oleh varietas ubi kayu yang ditanam. Kualitas tumbuhan memegang peranan dalam dinamika populasi hama melalui pengaruhnya terhadap perkembangan pradewasa dan imagonya. Berbagai varietas ubi kayu yang ada di Indonesia memiliki kandungan senyawa sianida yang berbeda (Balitkabi, 2005). Dalam penelitian ini dibandingkan berbagai parameter hayati $P$. manihoti pada dua varietas ubi kayu yaitu UJ-5 dan Adira-1 yang memiliki kadar sianida yang berbeda.

Menurut hasil penelitian Tertuliano et al. (1993, 1999), ketahanan varietas ubi kayu terhadap kutu putih berkaitan dengan senyawa sekunder seperti sianida. Kutu P. manihoti merupakan serangga yang mengambil makanan dengan cara mengisap cairan pada jaringan floem, yang di dalamya terdapat senyawa sianida. Menurut Catalayud et al. (1994a) senyawa sianida berperan sebagai fagostimulan untuk kutu $P$. manihoti. Tampaknya kutu putih $P$. manihoti mampu mengembangkan mekanisme fisiologis yang dapat mengubah sianida yang bersifat toksik menjadi bahan yang tidak toksik atau bahkan menjadi bahan nutrisi (Catalayud et al. 1994b). Catalayud et al. (1994a) melaporkan tidak terdapat hubungan antara laju pertumbuhan populasi $\left(\mathrm{r}_{\mathrm{m}}\right) P$. manihoti dengan kandungan senyawa primer (asam amino dan gula) yang terdapat pada daun berbagai varietas ubi kayu.

Dalam penelitian ini ditunjukaan bahwa perbedaan varietas ubi kayu yang memiliki kadar sianida berbeda berpengaruh terhadap kehidupan pradewasa kutu putih P. manihoti. Masa inkubasi telur berlangsung 7,93 hari pada UJ-5 dan 8,33 hari pada Adira-1. Pengaruh yang lebih nyata tampak pada masa perkembangan nimfa. Nimfa yang hidup pada UJ-5 memerlukan waktu 12 hari, sedangkan pada Adira-1 memerlukan 15 hari untuk perkembangannya hingga menjadi imago. Perbedaan varietas ubi kayu juga berpengaruh terhadap berbagai parameter kehidupan imago P. manihoti, khususnya terhadap keperidian. Walaupun masa hidup imago P. manihoti pada kedua varietas hampir sama yaitu sekitar 20 hari, banyaknya telur yang dihasilkan berbeda. Keperidian kutu putih yang dipelihara pada UJ-5 sebanyak 386 butir, sedangkan pada Adira-1 sebanyak 318 butir. Saputro (2013) yang meneliti biologi $P$. manihoti pada varietas Manggu mendapatkan keperidian 570 butir. Selain karena varietas, perbedaan keperidian ini diperkirakan karena perbedaan teknik pengamatan. Pada penelitian ini, keperidian didasarkan pada instar-1 yang ditemukan, sedangkan pada penelitian Saputro keperidian didasarkan pada penghitungan telur.

Pengaruh varietas ubi kayu terhadap kutu putih P. manihoti juga dapat diperiksa dari berbagai parameter neraca hayati, yang menggambarkan tingkat kesesuaian tumbuhan inang. Rataan masa generasi (T) kutu P. manihoti lebih singkat pada UJ-5 (22,8 hari) dibandingkan pada Adira-1 (25,5 hari). Perbedaan ini terkait dengan perbedaan masa perkembangan pradewasa dan keperidian kutu putih pada kedua varietas seperti telah disebutkan terdahulu. Sebaliknya, laju reproduksi bersih (Ro), yang merupakan kelipatan populasi per generasi, lebih besar pada UJ-5 ( 361) daripada Adira-1 (274). Begitu pula terdapat perbedaan yang nyata antara laju pertambahan intrinsik $\left(\mathrm{r}_{\mathrm{m}}\right)$

Tabel 3. Parameter pertumbuhan populasi ( \pm SE) Phenacoccus manihoti pada dua varietas ubi kayu

\begin{tabular}{cccc}
\hline \multirow{2}{*}{ Parameter } & \multicolumn{2}{c}{ Varietas } & \multirow{2}{*}{$\mathrm{P}$} \\
\cline { 2 - 3 } & $\mathrm{UJ}-5$ & Adira- & $<0,0001$ \\
\hline Ro & $361,040 \pm 5,429$ & $274,630 \pm 2,520$ & $<0,0001$ \\
$\mathrm{r}_{\mathrm{m}}$ & $0,258 \pm 0,0008$ & $0,220 \pm 0,0005$ & $<0,0001$ \\
$\mathrm{~T}$ & $22,795 \pm 0,050$ & $25,532 \pm 0,047$ & $<0,0001$ \\
$\mathrm{Dt}$ & $2,683 \pm 0,008$ & $3,152 \pm 0,007$ & $<0,0001$ \\
$\lambda$ & $1,295 \pm 0,0009$ & $1,246 \pm 0,0006$ & \\
\hline
\end{tabular}


P. manihoti pada dua varietas ubi kayu yang diuji. Nilai $\mathrm{r}_{\mathrm{m}}$ kutu $P$. manihoti pada varietas UJ-5 $(0,258)$ lebih tinggi daripada varietas Adira-1 $(0,220)$. Pada varietas Manggu yang kandungan sianidanya rendah, Saputro (2013) mendapatkan nilai $\mathrm{r}_{\mathrm{m}}=0,213$. Nilai $\mathrm{r}_{\mathrm{m}}$ yang jauh lebih rendah $(0,133)$ dilaporkan terjadi pada varietas Incoza yang tergolong tahan terhadap $P$. manihoti di Afrika (Tertuliano et al., 1993). Karena laju pertambahan intrinsic $\left(\mathrm{r}_{\mathrm{m}}\right)$ menggambarkan pengaruh komposit dari perkembangan, keperidian, dan sintasan, maka $\mathrm{r}_{\mathrm{m}}$ dapat dijadikan indeks untuk mengukur kualitas nutrisi atau tingkat resistensi tumbuhan inang (Southwood \& Henderson, 2000). Lebih tingginya nilai $\mathrm{r}_{\mathrm{m}}$ pada UJ-5 mengisyaratkan potensi peningkatan populasi P. manihoti yang lebih cepat pada varietas ini.

Keseluruhan hasil penelitian mengungkapkan bahwa perkembangan, reproduksi, dan sintasan $P$. manihoti sangat dipengaruhi oleh varietas ubi kayu. Dari penelitian ini juga ditunjukkan bahwa potensi laju pertumbuhan populasi $P$. manihoti lebih tinggi pada varietas UJ-5 yang mengandung sianida yang tinggi. Pengetahuan ini sangat penting, terutama karena pada saat ini pemerintah sedang menggalakkan penanaman ubi kayu varietas UJ-5 pada skala luas untuk kepentingan industri bioetanol. Dalam kaitan ini, kutu putih P. manihoti dapat menjadi ancaman serius bagi upaya peningkatan produksi ubi kayu di Indonesia. Hasil penelitian yang dilakukan barulah memberikan landasan awal bagi penyusunan program pengelolaan hama terpadu kutu $P$. manihoti. Penelitian lebih lanjut perlu dilakukan untuk memahami dinamika populasi P. manihoti di lapangan, terutama dalam kaitannya dengan peranan musuh alami lokal.

\section{SIMPULAN}

Ubi kayu varietas UJ-5 lebih sesuai bagi kehidupan dan peningkatan populasi kutu putih $P$. manihoti. Hal ini ditunjukkan oleh masa perkembangan pradewasa yang lebih singkat dan keperidian yang lebih tinggi. Analisis neraca hayati mengungkapkan nilai $\mathrm{r}_{\mathrm{m}}$ yang lebih tinggi pada UJ-5. Oleh karena itu, penanaman ubi kayu varietas UJ-5 pada skala luas perlu mengantisipasi perkembangan serangan kutu $P$. manihoti.

\section{SANWACANA}

Penelitian ini merupakan bagian dari rangkaian penelitian yang dilakukan oleh penulis pertama dalam rangka penyelesaian studi S3 di Institut Pertanian Bogor, dengan beasiswa dari Badan Penelitian dan Pengembangan Pertanian, Kementerian Pertanian. Ucapan terimakasih disampaikan kepada Bapak Wawan Yuwandi yang telah membantu pelaksanaan penelitian.

\section{DAFTAR PUSTAKA}

Awmack CS \& Leather SR. 2002. Host plant quality and fecundity in herbivorous insects. Annu. Rev. Entomol. 47: 817-844.

Balitkabi 2005. Teknologi Produksi KacangKacangan dan Umbi-umbian. Balitkabi, Malang.

Bellotti AC, Smith L, \& Lapointe SL. 1999. Recent advances in cassava pest management. Annu. Rev. Entomol 44: 343-370.

Birch LC. 1948. The intrinsic rate of natural increase of an insect population. J. Animal Ecol. 17: 1526.

Catalayud PA \& Le Ru B. 2006. Cassava-Mealybug Interactions. Institut de Reserche Pour le Development, Paris.

Calatayud PA, Rahbé Y, Delobel B, Khuong-Huu E, Tertuliano M, \& Le Ru B. 1994a. Influence of secondary compounds in the phloem sap of cassava on expression of antibiosis towards the mealybug Phenacoccus manihoti. Entomol. Exp. Appl. 72: 47-57.

Catalayud PA, Tertuliano M, \& Le Ru B. 1994b. Seasonal changes in secondary compounds in the phloem sap of cassava in relation to plant genotype and infestations by Phenacoccus manihoti (Homoptera: Pseudococcidae). Bull. Entomol. Res. 84: 453-459.

Maia AHN, Luiz AJB, \& Campanhola C. 2000. Statistical inference on associated life table parameters using jacknife technique: computational aspect. J. Econ. Entomol. 93: 511518.

Nwanze KF. 1978. Biology of the cassava mealybug Phenacoccus manihoti Mat-Ferr. in the Republic of Zaire. In: Nwanze KF \& Leuschner K (Eds.). Proceedings of the International Workshop on Cassava Mealybug Phenacoccus manihoti MatFerr. (Pseudococcidae). pp. 20-28. INERA, M'Vuazi, Zaire, June 26-29, 1977. IITA Press, Ibadan, Nigeria. 
Nwanze KF. 1982. Relationships between cassava root yields and crop infestations by the mealybug, Phenacoccus manihoti. Int. J. Pest Manage. 28: 27-32.

Nwanze KF, Leuschner K, \& Ezumah HC. 1979. The cassava mealybug, Phenacoccus sp., in Republic of Zaire. PANS 25(2): 125-130.

Parsa S, Kondo T, \& Winotai A. 2012. The cassava mealybug (Phenacoccus manihoti) in Asia: First records, potential distribution, and an identification key. PloS ONE 7(10): e47675. doi.10.1371/ journal.pone.0047675.

Rauf A. 2011. Invasive pests. In: IPM CRSP Annual Report 2010-2011, p. 100.

Saputro AR. 2013. Biologi dan potensi peningkatan populasi kutu putih singkong, Phenacoccus manihoti Matile-Ferrero (Hemiptera: Pseudococcidae): Hama pendatang baru di Indonesia. Skripsi. Fakultas Pertanian-IPB, Bogor.
Southwood TRE \& Henderson PA. 2000. Ecological Methods. Third Edition. Blackwell Sci., Oxford.

Soysouvanh P \& Siri N. 2013. Population abundance of pink mealybug, Phenacoccus manihoti on four cassava varieties. Khon Kaen Agr. J. 41(1): 149153.

Tertuliano M, Calatayud PA, \& Le Rü BP. 1999. Seasonal changes of secondary compounds in the phloem sap of cassava in relation to fertilisation and to infestation by the cassava mealybug. Insect Sci. Appl. 19(1): 91-98.

Tertuliano M, Dossou-Gbete S, \& Le Ru B. 1993. Antixenotic and antibiotic components of resistance to the cassava mealybug Phenacoccus manihoti (Homoptera: Pseudococcidae) in various host-plants. Insect. Sci. Appl 14(5): 657665.

Winotai A, Goergen G, Tamò M, \& Neuenschwander P. 2010. Cassava mealybug has reached Asia. Biocontrol News Inf. 31: 10-11. 